\title{
O ESTÍMULO AO CONSUMO COMO FORMA DE PODER: OS IMPACTOS NO MEIO AMBIENTE
}

\section{THE STIMULUS POWER CONSUMPTION AS FORM: THE IMPACT ON THE ENVIRONMENT}

\author{
${ }^{1}$ Gabriella de Castro Vieira \\ ${ }^{2}$ Carlos Frederico Saraiva De Vasconcelos
}

\section{RESUMO}

O presente trabalho aborda o poder do consumidor, o incentivo ao consumismo e os impactos no meio ambiente. O objetivo geral do artigo é analisar como o poder tem sido praticado na sociedade pós-moderna, tendo por eixo central o consumo desenfreado e os reflexos ambientais. Para tanto, é realizada uma abordagem geral acerca da importância do consumidor para o mercado, os dispositivos legais que lhe tutelam, o poder do setor publicitário, destacando-se o consumismo compulsivo. Posteriormente, analisam-se os impactos ambientais e discute-se a responsabilidade de todos os agentes a respeito do consumo consciente e a sustentabilidade.

Palavras-chave: Consumidor, Poder, Consumismo, Impacto ambiental, Ética, Sustentabilidade

\begin{abstract}
This paper discusses the power of the consumer, encouraging consumption and environmental impacts. The overall objective of this article is to analyze how the power has been practiced in post-modern society, with the central axis unbridled consumption and environmental consequences. Therefore, a general approach is held on the importance of the consumer to the market, the legal provisions which protect you, the power of the advertising industry, especially the compulsive consumerism. Subsequently, we analyze the environmental impacts and discusses the responsibility of all stakeholders about conscious consumption and sustainability.
\end{abstract}

Keywords: Consumer, Power, Consumerism, Environmental impact, Ethic, Sustainability

\footnotetext{
${ }^{1}$ Mestranda em Direito pela Escola Superior Dom Helder Câmara em Minas Gerais - Dom Helder, Minas Gerais (Brasil). Professor de Direito pela Sociedade Educacional de BH - ANHANGUERA, Minas Gerais (Brasil). E-mail: gabivieirabh@ hotmail.com

${ }^{2}$ Mestrando em Direito Ambiental e Desenvolvimento pela Escola Superior Dom Helder Câmara em Minas Gerais - Dom Helder, Minas Gerais (Brasil). Professor pela Faculdade de Estudos Administrativos de Minas Gerais - FEAD, Minas Gerais (Brasil). E-mail: carlossaraiva.adv@terra.com.br
} 


\section{INTRODUÇÃO}

A temática ambiental, ligada ao consumo vem ganhando cada vez mais ênfase na sociedade de risco em que vivemos, gerando uma dúvida sobre o quão o mundo irá suportar os níveis de consumo crescente e os seus refugos.

A sustentabilidade como direito fundamental no resguardo do mínimo vital ganha uma repercussão especial uma vez que o estilo de consumo assume uma identidade cultural no cultivo do "ter".

As inovações tecnológicas levam cada vez mais o homem a criar uma identidade com a inovação, e na sua busca para a atualização o esgotamento do bem de consumo dentro de toda a sua longevidade é relegado ao segundo plano.

Obviamente que esse estilo de vida se coloca em choque com os direitos fundamentais, gerando os novos direitos clamados pela humanidade seguem a evolução da terceira dimensão dos direitos humanos, agregando um valor transcendental subjetivo, indo além do ponderável individual ou coletivo, para todo ser humano, pelo simples fato de serem seres humanos.

A solidariedade é expressão maior do direito a ter direitos, elevando essa condição à categoria maior, pois quanto mais evolui a humanidade, cada vez mais se tem a necessidade de identificar e apontar os novos direitos e projetar os novos instrumentos de tutela. Tudo isso sem que toda essa classificação se perca no "ostracismo", por se mostrar inatingível, suscitado apenas no aspecto hermenêutico e filosófico.

Não se deve levantar uma bandeira de ódio ao consumo, mas a importância da preservação ambiental e cooperação entre os povos é uma condição básica à qualidade de vida.

A afetação do meio ambiente não é mais um acontecimento que atinge certa região apenas, já que as agressões ambientais começavam a se tornar um problema mundial, atingindo tanto nações desenvolvidas como em desenvolvimento, prejudicando a qualidade de vida no planeta, independentemente do poderio econômico da nação.

Assim, a elevação do meio ambiente ao caráter difuso, consagra a proteção e preocupação ambiental como um "novo direito", onde não é somente necessária a busca e identificação das agressões e ofensas ambientais, que geram consequências negativas à humanidade. 
Preservar as liberdades individuais, conquistadas com os ideais liberais pregados por Adam Smith, Montesquieu, Rousseau entre outros é tão importante quanto se preservar o direito à vida, dentro de um meio ambiente sadio e preservado.

A busca pela sustentabilidade deve ser elevada ao primeiro plano, sem justificativas ou desculpas para o seu esquecimento ou mitigação, sendo a sua urgência um bem maior a ser buscado, como garantia de um mínimo vital.

Diante de tais questões, pretende o presente artigo lançar uma justificativa da temática proposta, demonstrando que o viés consumerista sem controle milita na contramão do sentido preservacionista do art. 225 da Constituição da República de 1988, que prevê a atuação compulsória do Estado Brasileiro, em todas as suas esferas, na defesa e preservação para a presente e futuras gerações.

Utiliza-se como método o hipotético-indutivo e a técnica de pesquisa explicativa qualitativa.

\section{O CONSUMIDOR}

Não restam dúvidas que o ato de consumir é fundamental para a sobrevivência da espécie humana. O consumo de determinados bens e produtos são essenciais à vida, como água, luz e alimentos.

Com o desenvolvimento científico-tecnológico surgiu o consumo de massa, que despertou, em decorrência do enorme potencial de crescimento, o interesse e investimento do setor empresarial.

Ciente da relevância do consumidor para a economia e da necessidade de proteção do poder público, em 15 de março de 1962 o presidente dos Estados Unidos da América encaminhou ao Congresso uma mensagem ressaltando a importância da criação de direitos para categoria. John Frietzgerald Kennedy discorreu:

Consumers, by definition, include us all. They are the largest economic group in the economy, affecting and affected by almost every public and private economic decision. Two-thirds of all spending in the economy is by consumers. But they are the only important group in the economy who are not effectively organized, whose views are often not heard. ${ }^{1}$

\footnotetext{
1 Tradução livre: “Os consumidores, por definição, inclui a todos nós. Eles são o maior grupo na economia, que influencia e é influenciado por quase todas as decisões públicas e privadas econômicas. Dois terços de todos os gastos da economia são efetuados pelos consumidores. Mas eles são o único grupo importante na economia que não é efetivamente organizado, cujos pontos de vista frequentemente não são ouvidos".

Disponível em: http://www.presidency.ucsb.edu/ws/?pid=9108. Acesso em: 30/07/2015
} 
A mensagem especial direcionada ao Congresso mencionou quatro direitos fundamentais dos consumidores: direito à segurança, à informação, à escolha e o direito de ser ouvido. Além da proteção da vida e da integridade física, e ao acesso à informação clara para viabilizar a liberdade de escolha, percebe-se que o chefe do poder executivo dos Estados Unidos pretendeu o reconhecimento do poder do consumidor no sentido de que seus interesses fossem considerados na elaboração de políticas públicas governamentais.

O discurso do presidente norte-americano se tornou um marco para a construção dos direitos do consumidor em grande parte do mundo. Nas palavras de Keila Pacheco Ferreira: “assim, a partir da década de 1960, as legislações que visam a proteção do consumidor emergem no seio das sociedades capitalistas industrializadas, em países que enfrentaram problemas similares, típicos de um economia liberal.” (FERREIRA, 2013, p. 555)

Anualmente comemora-se o dia internacional do consumidor em 15 de março, em homenagem ao feito de John Kennedy.

No dia 16 de abril de 1985, a Organização das Nações Unidas publicou a Resolução n $39 / 248$ sobre a proteção do consumidor, estabelecendo princípios gerais e convocando todos os países, especialmente os que se encontram em desenvolvimento, a criar e manter uma política de tutela. Dentre os vários direitos básicos elencados pela ONU, destacam-se a informação e a educação, além do incentivo à cooperação internacional entre os Estados em prol da defesa do consumidor. ${ }^{2}$

No cenário nacional o legislador constituinte brasileiro incluiu a defesa do Consumidor no Título II "Dos Direitos e Garantias Fundamentais”, Capítulo I "Dos Direitos e Deveres Individuais e Coletivos", da Constituição da República Federativa do Brasil:

Art. $5^{\circ}$ Todos são iguais perante a lei, sem distinção de qualquer natureza, garantindose aos brasileiros e aos estrangeiros residentes no País a inviolabilidade do direito à vida, à liberdade, à igualdade, à segurança e à propriedade, nos termos seguintes: $[\ldots]$

XXXII - o Estado promoverá, na forma da lei, a defesa do consumidor; (BRASIL, 1988)

Trata-se de um direito fundamental, o que implica em prestação protetiva do Estado, mediante atuação positiva em todos os três poderes: Judiciário, Executivo e Legislativo. A

2 Resolução n $\mathrm{n}^{\mathbf{0}} \quad 39 / 248 \quad$ - Organização das Nações Unidas Disponível em: http://www.un.org/documents/ga/res/39/a39r248.htm. Acesso em: 12/07/2015 
proteção constitucional vincula ao Estado, bem como a todos os intérpretes da lei, inclusive o setor privado.

Nesse sentido, além da obrigação estatal pela tutela do Consumidor, fora estabelecido no mesmo diploma constitucional, em seu Título VII, Capítulo I, que a Ordem Econômica e Financeira deve observar:

Art. 170. A ordem econômica, fundada na valorização do trabalho humano e na livre iniciativa, tem por fim assegurar a todos existência digna, conforme os ditames da justiça social, observados os seguintes princípios:

$[\ldots]$

$\mathrm{V}$ - defesa do consumidor;

VI - defesa do meio ambiente, inclusive mediante tratamento diferenciado conforme o impacto ambiental dos produtos e serviços e de seus processos de elaboração e prestação; (BRASIL, 1988)

Não restam dúvidas que o Estado Brasileiro ao regular a atividade econômica estabeleceu a proteção do consumidor e do meio ambiente objetivando o alcance de uma harmonia nas relações, mediante um efetivo equilíbrio, inclusive com a natureza ao estabelecer princípios que devem ser observados, uma vez que são de ordem pública.

Especificamente em relação ao consumidor, a tutela estatal visa evitar as abusividades praticadas em desfavor daquele que é mais vulnerável nos contratos de massa.

A respeito dos contratos de massa elucida Cristiano Heineck Schmitt:

A emergência do mercado de massa, fenômeno social, econômico e cultural do nosso tempo, decorrente da expansão industrial ocorrida no século XIX, modificou as estruturas tradicionais do contrato. Realizando mediante negociação individual, este tipo de contrato, gradualmente, cedeu espaço para o modelo estandardizado cuja estrutura se compõe de cláusulas preestabelecidas por um dos contratantes. Isso possibilitou, de um ponto de vista positivo, um ganho de tempo por ambas as partes, visto que praticamente inexiste a fase de tratativas, reduzindo-se os custos de contratação e ocasionando um aumento do número de relações jurídicas que se formam entre os indivíduos. Passaram a ser chamados de "contratos de massa", pois celebrados com toda a coletividade. A massificação e a despersonalização das relações contratuais fizeram surgir a figura do consumidor. (SCHMITT, 2008, p. 38/39)

Após a promulgação da Constituição da República Federativa do Brasil em 05 de outubro de 1988, vários diplomas infraconstitucionais sobre o direito do consumidor surgiram e, destaca-se, o Código de Defesa do Consumidor - Lei nº 8.078/1990.

Com os preceitos jurídicos sobre o tema pretende-se tutelar o consumidor, viabilizando o desenvolvimento econômico sustentável, mediante o equilíbrio, conforme dispõe a lei consumerista:

Art. $4^{\circ}$ A Política Nacional das Relações de Consumo tem por objetivo o atendimento das necessidades dos consumidores, o respeito à sua dignidade, saúde e segurança, a proteção de seus interesses econômicos, a melhoria da sua qualidade de 
vida, bem como a transparência e harmonia das relações de consumo, atendidos os seguintes princípios:

I - reconhecimento da vulnerabilidade do consumidor no mercado de consumo;

[...]

III - harmonização dos interesses dos participantes das relações de consumo e compatibilização da proteção do consumidor com a necessidade de desenvolvimento econômico e tecnológico, de modo a viabilizar os princípios nos quais se funda a ordem econômica (art. 170, da Constituição Federal), sempre com base na boa-fé e equilíbrio nas relações entre consumidores e fornecedores; (BRASIL, 1990)

Segundo a Nova Enciclopédia da Bioética:

A noção de vulnerabilidade exprime um dos aspectos mais universais da condição humana - a sua finitude e mortalidade. A descrição de um ser como vulnerável evoca, normalmente, um apelo ético de cuidados, de proteção e responsabilidade por esse ser. E, na comunicação ordinária, a noção de vulnerabilidade é, ao mesmo tempo, descritiva e normativa, um registro que constitui, desde logo, uma prescrição de tal modo que, numa ética da vulnerabilidade, a distinção entre os factos e as normas deixa de ser utilizável, pois a vulnerabilidade já é um conceito ético. Talvez esta dualidade explique por que motivo o princípio da vulnerabilidade se tornou, nos nossos dias, tão imperioso como princípio ético fundamental na bioética e, aliás, em qualquer consideração ética. (HOTTOIS e MISSA, 2003, p. 687)

A respeito do equilíbrio entre fornecedor e consumidor afirma Paulo Roque Khouri: "O CDC nada mais é do que uma tentativa de reequilibrar essa relação, tendo em vista a posição econômica favorável do fornecedor; impondo-se a necessidade de um equilíbrio mínimo em todas as relações contratuais de consumo". (KHOURI, 2012, p. 34)

Percebe-se a importância do consumidor para o desenvolvimento econômico, uma vez que a produção industrial, bem como a atividade de comércio, sempre foram praticadas com vistas a satisfazer as necessidades daquele mercado, inclusive as mais básicas.

Contudo, o mercado consumerista em muito se alterou, não se limitando apenas aos produtos e bens primordiais. Isto porque, no contexto atual, uma expressiva parcela da população mundial vive para consumir, em busca de aprovação social e de poder.

A sociedade contemporânea também pode ser denominada como Sociedade de Consumidores, dominada pelo crédito e pelo marketing, na qual o ser humano tem sido tratado como mercadoria atraente e almejada.

O sociólogo Zygmunt Bauman, em sua obra 'Vida para Consumo', afirma que ocorrera uma mudança de paradigma: Sociedade de produtores para a sociedade de consumidores e aduz que: "o mundo formado e sustentado pela sociedade de consumidores fica dividido entre as coisas a serem escolhidas e os que as escolhem; as mercadorias e seus consumidores: as coisas a serem consumidas e os seres humanos que as consomem." (BAUMAN, 2008, p. 20) 
Em função do crescente desenvolvimento científico-tecnológico o mercado dos meios de comunicação se consolidou, uma vez que as publicidades se tornaram grandes e eficazes instrumentos para persuadir o indivíduo a consumir cada vez mais. Isto porque as campanhas publicitárias funcionam para o setor industrial e produtivo como ferramentas de escoamento dos produtos e serviços criados.

O poder do consumidor brasileiro, adquirido nas duas últimas décadas com a estabilidade monetária, controle da inflação e oferta de crédito, fez com que o mercado de comunicação crescesse expressivamente, tanto em volume, quanto em aprimoramento, já que o encantamento do indivíduo pela mercadoria veiculada é a grande finalidade, por isso as técnicas de marketing estão, a cada dia, mais sofisticadas e requintadas.

\subsection{O poder da publicidade}

Decorrente do poder de consumo do brasileiro, o mercado se tornou um campo fértil para o setor publicitário, movimentando cifras bilionárias. Dados divulgados pela Revista Exame, no primeiro semestre de 2015, informam que o ano de 2014 o capital empregado na área cresceu o total de $8 \%$ (oito por cento) e as aplicações voltadas para a Televisão por assinatura superaram $30 \%$ (trinta por cento), o que comprova que cada vez mais se investe no poder de compra do consumidor.

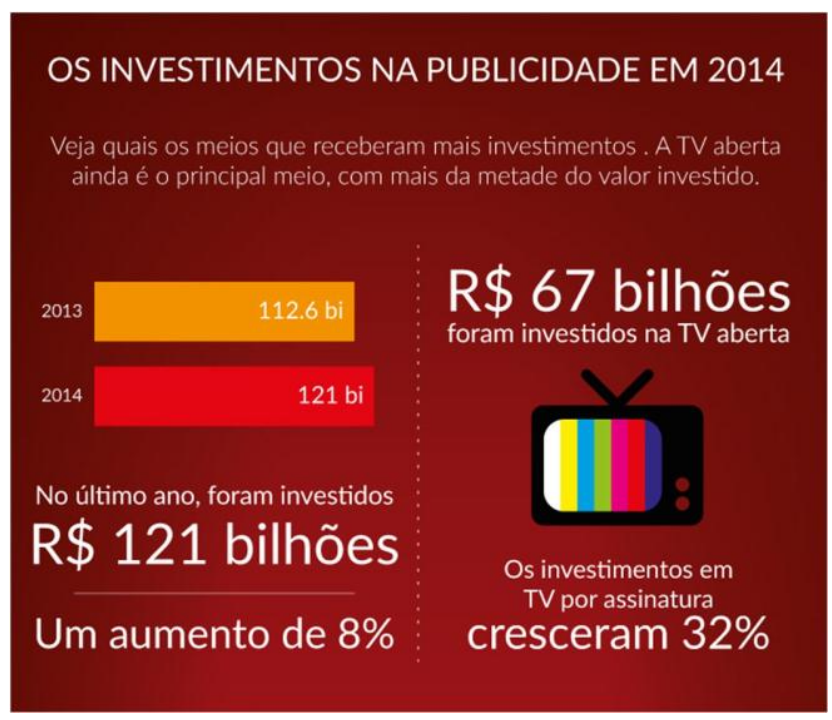

Figura $1^{3}$

\footnotetext{
${ }^{3}$ Revista Exame. Disponível em: http://exame.abril.com.br/marketing/noticias/o-raio-x-do-mercado-publicitarioem-2014. Acesso: 31/07/2015
} 
Destaca-se nesse campo a publicidade direcionada para o mundo virtual, que cresce a cada ano de forma muito expressiva. Segundo o canal de notícias G1, o Interactive Adversiting Bureau - IAB Brasil divulgou que: “ a publicidade digital deverá movimentar R\$ 9,5 Bilhões neste ano, uma alta de $14 \%$ frente a 2014 ".

Trata-se de um mercado muito rentável, o que faz com que diariamente os consumidores sejam bombardeados com publicidades sedutoras e agressivas, que constroem necessidades pela aquisição de novos produtos e serviços.

As campanhas de marketing são propositalmente elaboradas para incutir na mente do indivíduo que a felicidade, a satisfação, o status social e o poder somente serão alcançados mediante a aquisição de produtos e serviços de determinadas marcas.

As criações publicitárias utilizam-se de personagens felizes, saudáveis e bem dispostos, com o objetivo de conseguir o encantamento do consumidor pela marca, o que elucida a imagem abaixo:

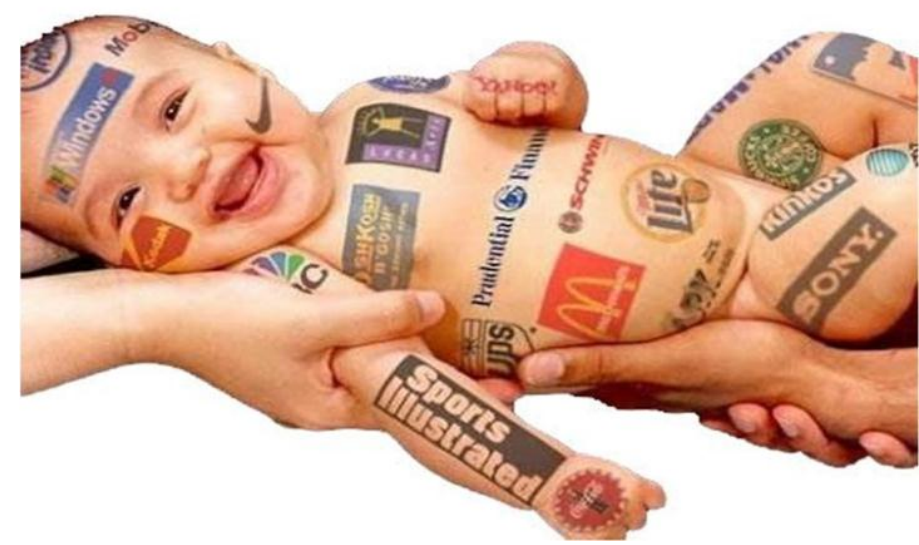

Figura $2^{5}$

A discorrer sobre o tema, o escritor e jornalista José Carlos Vieira, pondera sobre o poder da mídia e da propaganda como força maior em uma sociedade de consumo:

Vender uma imagem, uma ideia, um produto, se destacar na multidão de promessas e conquistas. Vivemos a era do Marketing, a exploração de uma marca, de um estilo, pessoa, e todos sabem o quanto é dramático ter um nome negativado no SPC. Uma imagem é veiculada na TV, jornal, WhatsApp, Facebook, e-mail, de todas as formas e vertentes possíveis. Há muitas pessoas mostrando mais do que valem e também

4 G1. Disponível em: http://g1.globo.com/economia/midia-e-marketing/noticia/2015/04/publicidade-digitaldeve-crescer-14-em-2015-aponta-pesquisa.html. Acesso em: 31/07/2015

5 http://queconceito.com.br/wp-content/uploads/publicidade.jpg. Acesso em: 30/07/2015 
valendo mais de que mostra, mas quem se omitir ficará fora do mercado. Divulgar, valorizar, fazer a propaganda boca a boa, veicular uma imagem que será multiplicada milhares de vezes em todos os meios de comunicação. De repente, o mundo ficou pequeno com tanta exposição e caminhos para a fama, além do BBB e outras possibilidades imediatas. Tudo é modo de divulgação, seja um anúncio no jornal, uma propaganda de três segundos na TV, uma faixa com um nome ou ideia, a vinheta na emissora de rádio, a promoção na porta da loja em letras enormes dizendo que aquela roupa ou sapato está sendo vendido abaixo do preço. (DIÁRIO DA MANHÃ, 2015)

Cada vez mais as técnicas de marketing utilizadas tem sido aperfeiçoadas para que a mensagem absorvida pelo público alcance os dois objetivos principais: informação a respeito do produto ou serviço que está a venda, bem como a necessidade de adquiri-lo.

O grande sucesso do setor, comprovado pelos números acima demonstrados, decorre principalmente do fato de que as publicidades investem em conteúdos com forte apelo emocional, criando um ilusório sistema de valores.

Com a pretensão de adquirir e desfrutar os benefícios e o bem-estar supostamente proporcionados pelos produtos e serviços expostos à venda, o indivíduo se torna dependente do consumo, o que é denominado consumismo, pois o ato de consumir não se restringe mais para as necessidades básicas, mas para satisfação pessoal, prazer e aprovação social.

\section{O CONSUMISMO COMPULSIVO E OS IMPACTOS NO MEIO AMBIENTE}

A necessidade do ser humano pela aquisição cada vez mais constante de bens e serviços criou o fenômeno do consumismo, vivenciado na sociedade atual e que tem trazido consequiências nefastas para o meio ambiente.

Sobre o consumismo Zygmunt Bauman, afirma:

Pode-se dizer que o "consumismo" é um tipo de arranjo social resultante da reciclagem de vontades, desejos e anseios humanos rotineiros, permanentes e, por assim dizer, "neutros quanto ao regime", transformando-os na principal força propulsora e operativa da sociedade, uma força que coordena a reprodução sistêmica, a integração e estratificação sociais, além da formação de indivíduos humanos, desempenhando ao mesmo tempo um papel importante nos processos de auto-identificação individual e de grupo, assim como na seleção e execução de políticas de vida individuais. O "consumismo" chega quando o consumo assume o papel-chave que na sociedade de produtores era exercido pelo trabalho. Como insiste Mary Douglas, "a menos que saibamos porque as pessoas precisam de bens de luxo [ou seja, bens que excedem as necessidades de sobrevivência] e como os utilizam, não estaremos nem perto de considerar com seriedade os problemas da desigualdade (BAUMAN, 2008, p. 41).

Na sociedade pós-moderna o consumo ganhou uma importância na formação da identidade dos indivíduos, bem como na construção das relações sociais. Isto porque o ato de 
consumir produtos de última geração, realizar freqüentes viagens internacionais, freqüentar restaurantes de renome, adquirir veículos importados e tudo mais que é comercializado e instigado pelas publicidades sedutoras se tornou sinônimo de poder e felicidade.

Nunca se consumiu tanto como nas últimas décadas. Ocorre que o consumismo compulsivo criou a cultura do desperdício, do descartável. A prática do consumo desenfreado e impulsivo compromete diretamente a natureza. Tal relação entre consumo e meio ambiente é facilmente comprovada, uma vez que para que seja realizada a produção dos bens torna-se necessária a extração de recursos naturais, portanto quanto mais se consome, mais insumos são retirados da natureza, o que gera impacto direto em todo o bioma. Nas palavras de Rodolfo Fares Paulo: “...o homem se apropriou do meio ambiente visando sempre ao enriquecimento e ao crescimento material da sociedade, pouco se importando também com a exploração predatória que isso estava desencadeando sobre o meio ambiente, acreditando cegamente que esses meios seriam inesgotáveis." (PAULO, 2010, p. 180).

No último século com o aumento populacional, aumentou-se o consumo e, conseqüentemente cresceu a produção de lixo, que são os resíduos depositados na própria natureza e, grande parte, de forma incorreta, em decorrência da ausência de uma prática adequada de descarte.

Segundo o Senado Federal o Brasil é o quinto maior produtor de lixo e apenas $3 \%$ dos resíduos produzidos são reciclados, apesar de um terço de todo o lixo urbano ser potencialmente reaproveitável. Informa ainda que o pouco que é reciclado decorre do esforço dos catadores, demonstrando a negligência do governo em estabelecer políticas públicas em prol de um reaproveitamento eficaz daquilo que é produzido no pós-consumo. Noticia também que a produção de lixo aumentou $21 \%$ nos últimos anos, enquanto que a população cresceu $9,6 \%$ no mesmo período. ${ }^{6}$

\footnotetext{
${ }^{6}$ Senado Federal. Brasília. Disponível em: http://www12.senado.gov.br/jornal/edicoes/2014/04/24/brasil-e-oquinto-maior-produtor-de-lixo-urbano. Acesso em: 01/08/2015
} 


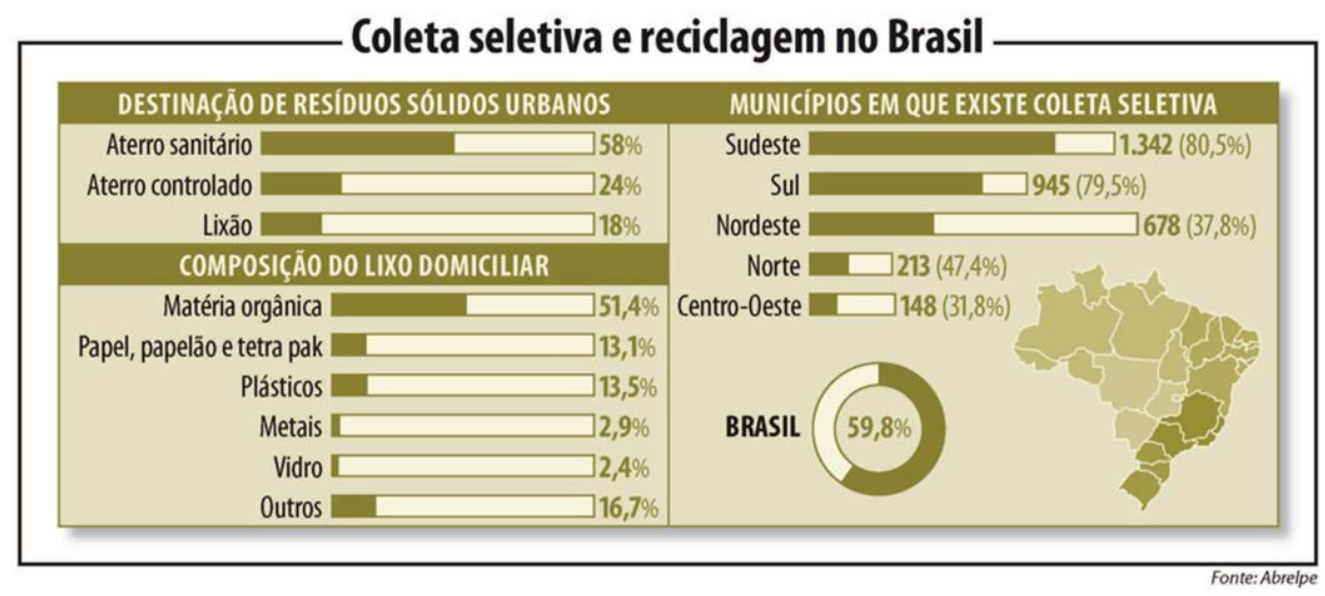

Figura 3

Nota-se pelos números apresentados pelo legislativo federal brasileiro que em função do expressivo aumento do consumo mais lixo tem sido fabricado e que a ausência de políticas em prol de um reaproveitamento, como coleta seletiva e reciclagem, agravam ainda mais os impactos no meio ambiente, que são nocivos à própria espécie humana.

Grande parte dos resíduos decorrente do consumismo desenfreado é depositado em rios, mares, terrenos baldios e lixões. O ser humano consome de maneira irresponsável, vez que não realiza um destino adequado para o lixo que ele próprio produz.

Tanto lixo produzido diariamente é consequiência do consumismo por impulso, que decorre de necessidades criadas pelo mercado e, um dos maiores contribuintes para esse fenômeno mundial é o mercado publicitário, que em função do poder de compra do consumidor investe cada vez mais no setor.

Contudo, o consumo compulsivo tem gerado sérios problemas para a humanidade, pois além de prejudicar o próprio indivíduo que se torna dependente do ato de comprar, danos ao meio ambiente são enormes, como aquecimento global, poluição, o que compromete os recursos socioambientais.

\section{O PODER DO CONSUMO E A DISCUSSÃO ÉTICA SOBRE A SUSTENTABILIDADE}

Há muito se discute sobre eticidade nas relações de consumo, mas sem que se lance mão de uma discussão mais ampla, que é o combate ao consumo excessivo em prol da preservação ambiental. 
A relação entre consumo e meio ambiente integra um complexo de relações intersubjetivas que dada à implicação daquele, neste verifica-se facilmente que o mundo consome muito mais do que o ambiente é capaz de absorver.

O consumo é tratado de uma forma completamente equivocado, gerando cada vez mais o desejo de se ter algo a mais, que seja novo, muitas vezes desnecessário, sem se preocupar com o custo ambiental e toda matéria prima explorada.

O sistema neoliberal foi extremado ao seu último grau, iniciando uma reversão autodestrutiva, pois as próprias nações consumistas não suportam mais absorver o seu nível de produção e por consequência o descarte destes bens de consumo, gerando um caos típico da sociedade de risco.

Além da ganância e da cultura de se consumir mais do que o necessário, os padrões da vida moderna levam a um comportamento típico de se interiorizar o ser humano em suas casas, cada vez mais equipadas com toda a sorte de produtos de última geração e que têm duração frívola marcada por uma obsolescência programada.

Cada vez mais o conforto e o bem estar são priorizados, mas sem que se lance um olhar sobre a ética do comportamento consumista, uma vez que o sentimento de liberdade, como motivação do gozo das garantias fundamentais, obscurece o raciocínio do meio ambiente sadio como uma consecção do direito à vida.

Robert Alexy ao discorrer sobre o tema levanta a importância da preservação das garantias fundamentais em toda a sua essência:

Aquele que se baseia apenas no texto dos dispositivos sobre direitos fundamentais garantidos sem reservas necessariamente chega à conclusão de que não são possíveis restrições à liberdade de crença, à liberdade artística e ao direito de se recusar a prestar serviço militar. Contudo, há um certo consenso de que nem tudo aquilo que puder, de alguma forma, ser incluído no suporte fático de uma norma garantida sem reservas será, ao final, protegido pelo direito fundamental em questão (ALEXY, 2014, p. 124).

Não há como discorrer sobre o tema sem relevar a importância da garantia vital mínima, como forma de preservação do direito fundamental mais elementar e que dá razão a todos os outros, qual seja, a vida.

O poder do consumo remete a uma discussão ética sobre a necessidade de se "ter" cada vez mais, com vistas a um bem estar individual, sem se ater ao reuso, reciclagem ou mesmo a abstenção de aquisição de certo bem, em detrimento de um meio ambiente sadio e equilibrado. 
Sobre o tema discorreu Jügen Habermas ao abordar a eticidade do comportamento e a abstenção do comportamento individual em prol de um bem coletivo:

Se quisermos enfrentar questões que tratam da regulação de conflitos ou da persecução de fins coletivos sem empregar a alternativa dos conflitos violentos, temos que adotar uma prática de entendimento, cujos processo e pressupostos comunicativos, no entanto, não se encontram simplesmente à nossa disposição.

[...] A passagem da constatação de um dissenso ético para um nível superior de abstração do discurso da justiça, requerida pelos "diálogos neutros", a fim de se examinar, na base do reconhecimento desse dissenso, o que é do interesse de todos os participantes, se coloca então como um caso especial de regra geral de argumentação (HABERMAS, 1997, p. 36/37).

O verdadeiro sentido do consumo se dá no uso correto dos bens de consumo, com vistas o respeito ao meio ambiente e à sustentabilidade, sendo esse um verdadeiro ato de magnificência.

Sobre o assunto Aristóteles discorreu, atentando que a verdadeira magnificência está em se saber gastar a riqueza com obras duradouras:

O homem magnificente também apresta sua casa de maneira condigna com a sua riqueza (pois até uma casa é uma espécie de ornamento público), e gastará de preferencia em obras duradouras (pois são essas as mais belas), e em toda classe de coisas gastará o que for decoroso, pois as mesmas coisas não são adequadas aos deuses e aos homens, nem a um templo e a um túmulo. (ARISTÓTELES, 1979, p. 306).

É verdade que o ato de pura benevolência ao se pensar coletivamente implica um amadurecimento da sociedade como um todo, mas enquanto tal comportamento não é criado, deve o Estado tutelar e proteger o bem maior que é o meio ambiente sadio, como forma de garantia ao direito à vida.

Inúmeras são as normas que priorizam a defesa do meio ambiente, mas nenhuma combate o consumo inconsciente e exagerado, porque esta é uma ideia não difundida no ideal capitalista liberal, pois consumo gera riqueza, que proporciona desenvolvimento.

Mas desenvolvimento sem sustentabilidade estagna os meios de produção, pois uma busca constante por matéria prima sem denotar um retorno ao meio ambiente ocasiona gastos cada vez maiores, o que compromete toda a via produtiva natural.

Os danos gerados pelo consumo excessivo já são conhecidos por todos e são por demais nocivos, e aqueles que ainda não conhecemos nos trazem profunda angústia e insegurança, não havendo alternativa segura para o uso desregrado das novas tecnologias, sendo premente uma priorização de padrões éticos para o seu uso. 
Estes novos conflitos necessitam de novos direitos, que devem surgir dentro de uma visão e uma discussão ética dos resultados que se espera alcançar. A sociedade causadora desses riscos, reflexivamente, é a mesma que deve participar efetivamente dessa discussão para a busca dos novos direitos, que venham a tutelar todas as novas possibilidades com eles criadas, resguardando os atores principais, componentes da própria sociedade, as espécies não humanas e o meio ambiente.

O desenvolvimento econômico é necessário para o crescimento da humanidade, mas deve-se sempre traçar os contornos de segurança para limitar a abrangência dos produtos dessa tecnologia, uma vez que os direitos fundamentais já garantidos não podem ser subjugados ou esquecidos, em prol do moderno, dos novos direitos.

Para se enfrentar tais desafios, Zygmunt Bauman lança a pergunta "como se podem prever, minimizar, dramatizar ou desafiar os perigos sistematicamente produzidos como parte da modernização"? (BAUMAN 1997, p. 278/279).

As consequências trazidas pelo modelo liberal individualista, na busca pela garantia da liberdade econômica não mais se sustenta sem a contrapartida ambiental, sendo a sustentabilidade e a mudança de comportamentos individuais a única saída para o caos que se implantou.

A cultura do consumo sem necessidade não é sustentável como esclarece Fernando dos Reis Condesso:

[...] o planeta terra encontra-se, hoje, perante o dilema de viver uma "civilização" industrial e agrícola poluidora, conter uma população que cresce a um ritmo galopante e ter um patrimônio e recursos naturais, incessantemente, degradados pela humanidade, à escala mundial. Como vimos, os problemas ambientais situam-se, hoje, entre as principais questões mundiais. (CONDESSO, 2001, p. 39)

Todos os atores da temática global têm seus deveres na busca da sustentabilidade, como uma espécie de responsabilidade solidária, não bastando o comportamento liberal para se construir um pleno progresso, sendo necessário também a eticidade nas relações de consumo para se alcançar um verdadeiro desenvolvimento sustentável, através da responsabilidade social de sua atuação.

\section{CONSIDERAÇÕES FINAIS}

Após a pesquisa realizada, o trabalho demonstrou que o poder do consumidor é explorado de forma generalizada, uma vez que o dinamismo da economia depende da sua efetiva e massiva participação.

Com o desenvolvimento científico-tecnológico, vivenciado na sociedade pós- 
moderna, o consumidor adquiriu ainda mais poder, principalmente por meio das redes sociais e demais ferramentas digitais que se encontram à sua disposição.

A voz do consumidor pode comprometer a própria existência de uma empresa, pois o impacto do seu poder gera abalos às vezes irreversíveis, já que o mundo digital alcança um número ilimitado de indivíduos.

Não restam dúvidas que tal poder fora reconhecido pelo mercado publicitário, que em função do enorme potencial do consumidor, adquirido principalmente nas duas últimas décadas, mediante a estabilidade econômica e o controle da inflação, investe de forma agressiva no setor, com vistas a criar constantes necessidades, estimulando o consumismo compulsivo.

A grande questão que precisa ser analisada pela sociedade atual é: o poder do consumidor na economia deve ser utilizado de forma moderada e consciente, devendo, portanto, o incentivo ao consumismo ser revisto por todos os agentes, inclusive com regulação pelo poder público no sentido de minimizar as consequiências da prática desenfreada.

Nesse sentido, importante demonstrou-se a discussão acerca dos problemas do consumismo. Uma digressão histórica sobre a tutela do consumidor no direito internacional e nacional forneceu a base necessária para a compreensão da importância do assunto, pois se trata de uma categoria que possui poder, mas que, por sua vez, é vulnerável e precisa de proteção. Além disso, apresentou-se também a importância de se discutir o consumo sob um viés do meio ambiente, que também sofre com o aumento do consumo e a falta de planejamento dos resíduos dele decorrentes.

O consumidor precisa se valorizar e ter ciência do poder que possui e utilizar sua força em prol de uma melhoria no mercado de oferta de produtos e serviços, com vistas a implementar uma mudança de comportamento, na qual as empresas de todos os setores, inclusive a publicitária, passem a ser responsáveis pelas suas atividades, o que implica em posturas éticas e leais, com vistas a alcançar um efetivo desenvolvimento econômico sustentável.

Desta maneira, o artigo procurou colocar em discussão a questão do consumidor e o seu poder, cada vez mais disputado no mercado, bem como os impactos no meio ambiente, de maneira a demonstrar os problemas que o envolvem, abrindo espaço para debates e possíveis soluções para o assunto. 


\section{REFERÊNCIAS}

ALEXY, Robert. Teoria dos Direitos Fundamentais. Tradução de Virgílio Afonso da Silva. $2^{\circ}$ ed. $3^{\text {a }}$ tiragem - São Paulo: Malheiros Editores, 2014.

ARISTÓTELES. Ética à Nicômaco. In; Aristóteles. Metafísica (livro 1 e livro 2); Ética a Nicômaco; Poética. São Paulo: Abril, 1979 329p. v. 2. (Os pensadores).

BARRETO, Vicente de Paulo. O fetiche dos direitos humanos e outros temas. $2^{\circ}$ ed. rev. e ampl. - Porto Alegre: Livraria do Advogado Editora, 2013.

BAUMAN, Zygmunt. Vida para Consumo: a transformação das pessoas em mercadoria. Tradução Carlos Alberto Medeiros - Rio de Janeiro: Zahar, 2008.

BAUMAN, Zygmunt. A ética é possível num mundo de consumidores? Tradução Alexandre Werneck - Rio de Janeiro: Zahar, 2011.

BAUMAN, Zygmunt. Ética pós-moderna. São Paulo: Paulus, 1997.

BECK, Ulrich. Sociedade de risco: rumo a uma outra modernidade. Tradução de Sebastião Nascimento. São Paulo: Editora 34, 2011.

BECK, Ulrich; GIDDENS, Anthony; LASH, Scott. Modernização reflexiva: política, tradição, e estética na ordem social moderna. Tradução: Maria Amélia Augusto. Oeiras: Celta Editora, 2000.

BRAGA NETTO, Felipe Peixoto; FARIAS, Cristiano Chaves e ROSENVALD, Nelson. Curso de Direito Civil. Responsabilidade Civil. Salvador: Jus Podivm, 2014.

BRASIL. Constituição da República Federativa do Brasil. Congresso Nacional. Brasília, $1988 . \quad$ Disponível em: http://www.planalto.gov.br/ccivil_03/constituicao/constituicaocompilado.htm Acesso em $22 / 04 / 15$.

. Lei 6.938, de 31 de agosto de 1981. Dispõe sobre a política nacional do meio ambiente. Disponível em: http://www.planalto.gov.br/ccivil_03/leis/16938.htm. Acesso em 22/04/15.

Lei 8078, de 11 de setembro de 1990. Dispõe sobre a proteção do consumidor. Disponível em: http://www.planalto.gov.br/ccivil_03/leis/18078.htm. Acesso em $22 / 04 / 15$.

. Lei 12.305, de 02 de agosto de 2010. Institui a Política Nacional de Resíduos Sólidos; altera a Lei $\mathrm{n}^{\mathrm{o}}$ 9.605/1998 e dá outras providências. Disponível em: http://www.planalto.gov.br/ccivil_03/_ato2007-2010/2010/lei/112305.htm. Acesso em $14 / 05 / 15$

CONDESSO, Fernando dos Reis. Direito do Ambiente. Portugal: Almeidinha, 2001. 
COSTA, Beatriz Souza. Meio Ambiente como direito à vida: Brasil, Portugal e Espanha. Rio de Janeiro: Lumen Juris, 2013.

DIÁRIO DA MANHÃ. Brasília. O poder da publicidade na vida das pessoas (2015). Disponível em: http://www.dm.com.br/opiniao/2015/04/o-poder-da-publicidade-na-vida-daspessoas.html. Acesso em: 01 ago. 2015.

FERREIRA, Keila Pacheco. Evolução do Direito do Consumidor e o Desafio do Superendividamento: Panorama atual e perspectivas. In: LOPES, Teresa Ancona; LEMOS, Patrícia Faga Iglecias; RODRIGUES JÚNIOR, Otávio Luiz (Coord). Sociedade de Risco e Direito Privado: Desafios normativos, consumeristas e ambientais. São Paulo: Atlas, 2013, p. 553-578.

FOUCAULT, Michel. Nascimento da Biopolítica - Curso dado no College de France (1978-1979). Martins Fontes: São Paulo, 2008.

HABERMAS, Jügen, 1929- Direito de democracia: entre facticidade e validade, volume II. Tradução: Flávio Beno Siebeneicher. Rio de Janeiro: Tempo Brasileiro, 1997.

JONAS, Hans. O Princípio responsabilidade: ensaio de ética para a civilização tecnológica. Tradução do original alemão Marijane Lisboa, Luiz Barreto Montez. - Rio de Janeiro: Contraponto: Ed. PUC-Rio, 2006.

LEITE, José Rubens Morato e AYALA, Patrick de Araújo. Dano ambiental: do individual ao coletivo extrapatrimonial. São Paulo: Revista dos Tribunais, 2011.

LEITE, José Rubens Morato (coord). Dano Ambiental na sociedade de risco. São Paulo: Saraiva, 2012.

LEMOS, Patrícia Faga Iglecias. Direito Ambiental: Responsabilidade Civil e proteção ao meio ambiente. 3, ed. rev., atual. e ampl. São Paulo: Editora Revista dos Tribunais, 2010.

MACHADO, Paulo Affonso Leme. Direito Ambiental Brasileiro. 23 ${ }^{\text {a }}$ ed. São Paulo: Malheiros Editores LTDA, 2015

MACHADO, Paulo Affonso Leme. Direito à Informação e Meio Ambiente. São Paulo: Malheiros Editores LTDA, 2006.

NAVES, Bruno Torquato de Oliveira; BRITO, Franclim Jorge Sobral de. Segunda modernidade e responsabilidade: a questão ambiental a partir da interface entre tecnociência e ética à luz do pensamento de Hans Jonas. In: XXI Encontro Nacional do CONPEDI, 2012, Uberlândia. Anais do XXI Encontro Nacional do CONPEDI. Florianópolis: Fundação

Boiteux, 2012. v. 1. p. 1514-1530. Disponível em: http://www.publicadireito.com.br/artigos/?cod=3d8e28caf901313a. Acesso em 13/05/2015

PAULO, Rodolfo Fares. O desenvolvimento industrial e o crescimento populacional como fatores geradores do impacto ambiental. In: Revista Veredas do Direito. v. 7. n. 13/14. Belo Horizonte. Janeiro/Dezembro 2010. p. 173-189 
SANDEL, Michael J. O que o dinheiro não compra: os limites morais do mercado. Tradução de Clóvis Marques. 6 ${ }^{\mathrm{a}}$ ed. - Rio de Janeiro: Civilização Brasileira, 2014.

SARLET, Info Wolfgang. Direito Constitucional ambiental: Constituição, direitos fundamentais e proteção do ambiente. $2^{\circ}$ Ed. rev. e atual. - São Paulo: Editora Revista dos Tribunais, 2012. 